\title{
Consanguinity and psychiatric disorders: Qatar case study
}

\begin{abstract}
Objective: The objective of this study was to examine the pattern of marriage and tradition among Qatari psychiatric patients attending an outpatient psychiatry clinic in Doha, Qatar. The study also investigates the difference between consanguineous and non-consanguineous marriages among patients in relation to five major psychiatric disorders.

Methods: 412 Qatari patients who were diagnosed with schizophrenia, bipolar affective disorder, major depression, mixed anxiety and depression and obsessive compulsive disorder, and attended the outpatient psychiatry clinic at Hamad Medical Corporation (HMC), in Doha, Qatar in the period between August 2011 and March 2012, were examined. Data was collected from participants' medical records and from a face to face interviews using a semi-structured questionnaire.

Results: $46.9 \%$ were consanguineous and 43.6 were non-consanguineous. The overall rates of consanguineous and non-consanguineous marriages among participants were $47.1 \%$ and $52.9 \%$ respectively. No significant differences were observed between consanguineous and non-consanguineous marriages in relation to the five major psychiatric disorders.

Conclusion: The overall trend of study result revels no significant differences between consanguineous and non-consanguineous participants' percentages in relation to the five major psychiatric disorders. First cousin marriages were found to be the most frequent in comparison to other types of relationships. One of the limitations of this study was that no DNA analysis was carried out.
\end{abstract}

Keywords: consanguinity, outpatients, psychiatric disorders, Qatar
Volume II Issue 6 - 2020

\author{
Mohamed Abdelalaim Ibrahim,' Kaltham Ali \\ Al-Ghanim, ${ }^{2}$ Ali Ahmed Eltohami,' Elnour \\ Elnaiem Dafeeah' \\ 'Clinical Psychologist, Mental Health Service, Hamad Medical \\ Corporation (HMC), Qatar \\ ${ }^{2}$ The Social \& Economic Survey Research Institute, Qatar \\ University, Qatar
}

Correspondence: Kaltham Ali Al-Ghanim, The Social \&Economic Survey Research Institute, Qatar University, Qatar, Email Kaltham.alganim@qu.edu.qa

Received: September 30, 2020 | Published: November 17, 2020

\section{Introduction}

Historically consanguineous marriages were practiced among many countries around the world and go back for thousands of years. ${ }^{1}$ It was estimated that over one billion individuals globally were in consanguineous marriage. ${ }^{2}$ In the Middle East region, however, the rate of consanguineous marriages was estimated between 20 to 70 per cent..$^{3-7}$ In a more recent study, Bener 2011 found that the prevalence of consanguinity in Qatari population was 52\% making it one of the high rates comparable to countries in the region. ${ }^{8} \mathrm{He}$ found that first cousin marriages, similar to other results from the region, predominates all types of marriages and comprising $26.7 \%$. Comparable results were also observed in other countries in the region. ${ }^{9-12}$

The aim of this study was to examine the pattern of marriage and tradition among Qatari psychiatric patients attending an outpatient psychiatry clinic in Doha, Qatar. The study also investigates the difference between consanguineous and non-consanguineous marriages among patients in relation to five major psychiatric disorders including schizophrenia, bipolar affective disorder, major depression disorder, mixed anxiety and depression disorder and obsessive compulsive disorder.

\section{The social background of consanguineous marriages in Qatar}

Although Qatar and the other Gulf States are characterized by a nearly unparalleled period of rapid development, many aspects of social life remain grounded in the longstanding traditions of the region. Marriage is certainly one of those practices. Endogamous marriage practices remain the norm in Qatar and in all the Gulf States. Science has clearly demonstrated that many forms of endogamous marriage practices significantly increase the risk for genetic disorders and defects. This is particularly true of consanguineous marriage, which according to recent studies characterizes half of all marriages in the Gulf countries.

Abu zeid ${ }^{13}$ indicated that kinship system is the basic social system chapped the Arab social structure. Kinship diverges and ramifies so much so that each individual gets a first-degree kinship to the nuclear families to which he belongs, and there are thirty-three types of second-degree kinship, and one hundred and fifty type of third-degree kinship. This complex network of kinship gives light to a network of kinship relationships that represent a well-knit, coherent hierarchical genealogical structure based on lineage and descent from one ancestor and representing the family roots, extension over time and social outreach. ${ }^{14}$

This kinship groups, sometimes up to several thousands and stretching in different regions and communities. This network of relatives is subject to inherited patterns of collective behavior that impose endogamy marriages in order to ensure the continuation of the family. As a result of this system of kinship the network of relations extends to include the brothers and sisters on both the father's and mother's side, and then spreads to the uncles and aunts, their children, and their children's children. So, there are kinship net from cousins, uncles and aunts from both the father's and mother's side; cousins from the father's side are those who represent the extended family which 
support a numerus of hierarchical and serial kinship relationships. This kind of kinship relations is the bass for the clan, which reproduce a new clan by the time, and these clans are the foundation for the tribal system in Gulf States.

Marriage between cousins is the mechanism to maintain the continuity of the clan's cohesion and the tribal system continuity in the region. However, most of the population in the region, especially for those who have nomadic roots depend on the tribal system as a determinant of their social status in the urban class structure even in the urban areas. ${ }^{14,15}$ Because of this, we find that the percentage of marriages between relatives is still high in the region as a whole and in the study community. For example, the latest statistics in Qatar showed the percentage of marriage contracts according to the relationship of kinship in 201 that the marriage rate between Relatives are still high as it is reaching $42 \%$ of all cases marriage, despite awareness campaigns about dangers, of this type of consanguineous Marriage. The percentage of the marriages were the couple is having kinship relation from first degree (i.e. they are cousins) reached $25 \%$ of the total marriages contracts in 2018 , while the percentage was of marriages between second degree of cousins is $17 \%$, and the percentage of couple who are not relatives is nearly $58 \%$ of the total of marriages contracts for the year 2018. ${ }^{16}$

These statistics indicated that the marriages between cousins still high and still spreading pattern in the society.

\section{Consanguinity and diseases}

It was hypothesized that consanguinity might increase the risk of disease in comparison to non-consanguineous marriages. Bener and colleagues ${ }^{17}$ found that consanguineous parents had a significantly higher risk than non-consanguineous parents in a number of diseases including cancer, mental disorders, heart diseases, gastro-intestinal disorders, hypertension, hearing deficit, diabetes mellitus, blood disorders, and bronchial asthma. Other studies were found linking consanguinity to other genetic disorders and physical malformation. ${ }^{2,18,19}$

\section{Consanguinity and mental illness}

There are a number of studies documenting the association between consanguinity as a risk factor among parents of patients with mental disorders in the Middle East region. Mansour and associates 2009 found that parental consanguinity rates increase the risk for bipolar 1 disorder in their study in Al Mansoura in Egypt. ${ }^{20} \mathrm{~A}$ similar result was obtained for schizophrenic patients in relation to parental consanguinity rates. ${ }^{21}$ In another study carried out in Saudi Arabia Chaleby and Tuma ${ }^{22}$ did find that offspring of close blood relationships marriages (i.e., first and second cousin) were more likely to have a positive family history of schizophrenia compared to offspring of distant relatives or non-consanguineous marriages.$^{22}$ However, a study from Sudan found that schizophrenia was not significantly associated with first cousin marriages in the parents. ${ }^{23}$ Similarly, in a more recent community based study of 1184 Arab patients from Qatar it was found that a family history of schizophrenia was increased among parents of patients with schizophrenia compared to those without the disorder. ${ }^{24}$ $\mathrm{He}$ also found that consanguinity was found to be more among the patients with schizophrenia than non-schizophrenic subjects. Moreover, schizophrenia diagnoses were more frequent among the offspring of consanguineous parents than among the offspring of nonconsanguineous parents.
Similarly, in a relatively recent study carried out in Southern Israel investigating consanguinity among parents of inpatients Bedouin Arab patients with schizophrenia, Dobrusin and associates 2008 found a significantly higher rate of parental consanguinity among patients with schizophrenia compared to controls. ${ }^{25}$

It was clearly evident from the cited literature that most studies relating consanguinity and mental disorders focused mainly on schizophrenia and few bipolar affective disorder studies. However, no studies were found relating consanguinity to other mental disorders. This study is trying to investigate the difference between consanguineous and non-consanguineous patients' in relation to five major psychiatric disorders including schizophrenia, bipolar affective disorder, major depression, mixed anxiety and depression disorder and obsessive compulsive disorder. To our knowledge, this study is the first of its kind in which five major psychiatric disorders were studied together in relation to consanguineous marriages relationships. This will reflect in giving a better perspective of the five major psychiatric disorders in relation to consanguinity. This study also adds some perspectives in improving the quality of lives of the general population in Qatar and the psychiatric patients and their families in particular in accordance with Qatar National Mental Health Strategies 2013-2018.

\section{Methods}

This is a cross-sectional descriptive study conducted in Doha, the State of Qatar at the department of psychiatry, Rumailh Hospital, Hamad Medical Corporation (HMC), which is the main psychiatric facility providing comprehensive psychiatric care for inpatients, outpatients and community psychiatric services. The study was conducted in 2012.

\section{Participants}

A sample comprises of 412 Qatari psychiatric patients with active medical records were recruited for this study over a period of six months. 175 participants were males and 237 were females with a mean age and standard deviation of 45.8/14.9. All participants are fulfilling the International Classification of Diseases (ICD-10) diagnostic criteria for the five major psychiatric diagnoses which are schizophrenia, bipolar affective disorder, major depression disorder, mixed anxiety and depression disorder and obsessive compulsive disorder were studied. Participants with organic brain disease, substance abuse, epilepsy and mental retardation were excluded.

This study was approved by the Medical Research Committee (MRC) at Hamad Medical Corporation. Participants were recruited during their routine scheduled appointments with their treating psychiatrist and as part of their follow-up assessment, as per Joint Commission International (JCI) guidelines, were informed about the study after it was thoroughly explained to them by two experienced psychiatric nurses appointed specifically for this job and supervised by the primary investigator who is a senior consultant psychiatrist. All participants were provided a formal consent form in Arabic language and only those agreed to participate were enrolled in the study. It is important to mention that all participants were very cooperative and that none of those approached decline to participate.

A semi-structured face-to-face interview suiting the purpose of the current study was used. The demographic characteristics and diagnoses were drawn from participants' active medical records. Information regarding the degree of relationship for consanguineous and non- 
consanguineous subjects were collected directly from participants and their accompanying relatives during the interview. Marriages between relatives were classified in seven groups: First cousin, first cousin once removed, double first cousin, second cousin, second cousin once removed, third cousin, and lastly same tribe. For statistical reasons, due to smaller numbers of some of these groups, the seven initial grouping was re-arranged into three main categories. First cousin and first cousin once removed and double first cousin were categorized as first cousin; second and second cousin once removed and third cousin were combined as one group and same tribe category remains as it is. Data regarding the direction of consanguineous relationship (parental/ maternal), the main income provider and whether participants receive social benefit were also gathered during the interview. All other missing data in the medical records of participants which are needed for the purpose of the study was obtained during the direct interview.

\section{Statistical analysis}

The Statistical Package for Social Sciences (SPSS) was used for statistical analysis. In this study the Pearson Chi-squared test was used to ascertain the association between two or more categorical variables. The level $p<0 \bullet 05$ was the cut-off value for significance.

\section{Results}

The mean age and standard deviation of the 412 participants interviewed was 45.8(14.9). The mean age and standard deviation of males and females were 43.1(14.8) and 47.8(14.9) respectively. The mean age and standard deviation of consanguineous and non-consanguineous subjects were 46.9(15.6) and 43.6(13.4) consecutively (Table 1). The majority of participants were females $(57.5 \%)$ compared to males $(42.5 \%)$

Table I Variables of study

\begin{tabular}{|c|c|c|c|c|}
\hline Variables & & Consanguineous & Non-consanguineous & Subtotal \\
\hline & Males & $84(20.4 \%)$ & $91(22.1)$ & $175(42.5)$ \\
\hline \multicolumn{5}{|l|}{ Gender } \\
\hline & Females & 110 (26.7) & 127 (30.8\%) & 237 (57.5\%) \\
\hline & Employed & & & $96(23.3 \%)$ \\
\hline & & $43(10.4 \%)$ & $53(12 / 9 \%)$ & \\
\hline & Unemployed & & & $273(66.3 \%)$ \\
\hline & & |3|(3|.8\%) & |42(35.5\%) & \\
\hline \multirow[t]{5}{*}{ Occupation } & Retired & & & $25(6.1 \%)$ \\
\hline & & I I (2.7\%) & $14(3.4 \%)$ & \\
\hline & Student & & & $15(3.6 \%)$ \\
\hline & & $07(1.7 \%)$ & $08(1.9 \%)$ & \\
\hline & Missing data & & & $03(0.7 \%)$ \\
\hline \multirow[t]{10}{*}{ Age } & Mean/SD & $46.9(15.6)$ & $43.6(13.4)$ & $45.8(14.9)$ \\
\hline & 15 to 24 & I7(4.I\%) & $08(1.9 \%)$ & $25(6 \%)$ \\
\hline & 25 to 34 & $42(10.2 \%)$ & $36(8.7 \% 0$ & $78(18.9 \%)$ \\
\hline & 35 to 44 & $49(11.9 \%)$ & $53 \mid 2.9 \%)$ & $102(24.8 \%)$ \\
\hline & 45 to 54 & $48(11.7 \%)$ & $43(11.7 \%)$ & $91(22.1 \%)$ \\
\hline & 55 to 64 & $30(7.3 \%)$ & $4 I(9.9 \%)$ & $7 \mathrm{I}(17.2 \%)$ \\
\hline & 65 to 74 & $04(0.9 \%)$ & $235.6 \%)$ & $27(6.5 \%)$ \\
\hline & $75+$ & 04() $.9 \%)$ & |43.4\%) & $18(4.3 \%)$ \\
\hline & Schizophrenia & $59(\mid 4.3 \%)$ & $64(15.5 \%)$ & $123(29.8 \%)$ \\
\hline & Bipolar & $34(8.3 \%)$ & $31(7.5 \%)$ & $65(15.8 \%)$ \\
\hline \multicolumn{5}{|l|}{ Diagnosis } \\
\hline & Depression & $5 \mathrm{I}(12.4 \%)$ & $76(18.4 \%)$ & $127(30.8 \%)$ \\
\hline & OCD & $19(4.6 \%)$ & $25(6.1 \%)$ & $44(10.7 \%)$ \\
\hline & Anxiety/depression & $3 \mathrm{I}(7.5 \%)$ & $22(5.3 \%)$ & $53(12.8 \%)$ \\
\hline
\end{tabular}




\begin{tabular}{|c|c|c|c|c|}
\hline Variables & & Consanguineous & Non-consanguineous & Subtotal \\
\hline \multirow{4}{*}{ Duration of illness } & $<5$ years & $48(11 \%)$ & $58(\mid 4.1 \%)$ & $106(25.8 \%)$ \\
\hline & 5 to 9 years & $58(14.1 \%)$ & $54(13.1 \%)$ & II $2(27.2 \%)$ \\
\hline & 10 to 14 years & $31(7.5 \%)$ & $29(7 \%)$ & $60(14.5 \%)$ \\
\hline & $>15$ years & $57(13.8 \%)$ & $77(18.7 \%)$ & $134(32.5 \%)$ \\
\hline \multirow{2}{*}{ Family support } & Good & 127 (30.8\%) & $15 \mid(36.6 \%)$ & $278(67.4 \%)$ \\
\hline & Average & $67(16.3 \%)$ & $67(16.3 \%)$ & $134(32.6 \%)$ \\
\hline \multirow{5}{*}{ Social Benefit } & Yes & & & $123(29.9 \%)$ \\
\hline & & $60(14.6 \%)$ & $63(15.3 \%)$ & \\
\hline & NO & & & $276(67 \%)$ \\
\hline & & $126(30.6 \%)$ & $150(36.4 \%)$ & \\
\hline & Missing data & & & $013(3.1 \%)$ \\
\hline \multirow{2}{*}{ Family History } & Present & $53(12.9 \%)$ & $44(10.7 \%)$ & $97(23.6 \%)$ \\
\hline & Absent & $|4|(34.2 \%)$ & $174(42.2 \%)$ & $312(76.4 \%)$ \\
\hline \multirow{12}{*}{ Income provider } & Parent & & & $06(1.5 \%)$ \\
\hline & & $04(1 \%)$ & $02(0.5 \%)$ & \\
\hline & Father & & & $45(11 \%)$ \\
\hline & & $32(7.8 \%)$ & $13(3.2 \%)$ & \\
\hline & Mother & & & $12(2.8 \%)$ \\
\hline & & $06(1.4 \%)$ & $06(1.4 \%)$ & \\
\hline & Self & & & $204(49.5 \%)$ \\
\hline & & $89(21.6 \%)$ & $115(27.9 \%)$ & \\
\hline & Husband & & & $95(23 \%)$ \\
\hline & & $43(10.4 \%)$ & $52(12.6 \%)$ & \\
\hline & Other & & & $46(11.2 \%)$ \\
\hline & Missing data & $19(4.6 \%)$ & $27(6.6 \%)$ & $04(0.9)$ \\
\hline \multirow{5}{*}{ Stability of illness } & Stable & & & $387(93.9 \%)$ \\
\hline & & I79(43.4\%) & $208(50.5 \%)$ & \\
\hline & Unstable & & & $19(4.6 \%)$ \\
\hline & & II(2.7\%) & $08(1.9 \%)$ & \\
\hline & Missing data & & & $06(1.5 \%)$ \\
\hline \multirow{6}{*}{ Spouses Kinship } & Yes & & & $124(30.1 \%)$ \\
\hline & & $64(15.5 \%)$ & $60(14.6 \%)$ & \\
\hline & NO & & & $134(32.6 \%)$ \\
\hline & & $53(12.9 \%)$ & $81(19.7 \%)$ & \\
\hline & Single & & & $086(20.9 \%)$ \\
\hline & Missing data & $5 \mathrm{I}(12.4 \%)$ & $35(8.5 \%)$ & $068(16.5 \%)$ \\
\hline
\end{tabular}

Table 1 also shows others variables including occupation, whether participants are receiving social benefit, family history of psychiatric disorder, the primary income provider, the duration of the psychiatric disorder and level of social support. $23.5 \%$ of participants have family history of mental disorder. The majority of participants (66.3\%) were unemployed. Also, $49.5 \%$ participants were the main income providers and $29.9 \%$ of them receive social benefit. The duration of participants' psychiatric disorders significantly varies with those exceeding 15 years comprise the biggest group across the main five disorders.

Table 1 also shows the socio-demographic characteristics of participants in relation to the diagnosis of their psychiatric disorders. Although there are apparent differences between consanguineous and non-consanguineous subjects in relation to their diagnosis, however, these differences were not significant (Figure 1). 
Fig. 1 Consanguineous and non-consanguineous subjects in relation to diagnosis

$\square$ Consanguineous subjects $\square$ Non-consanguineous subjects
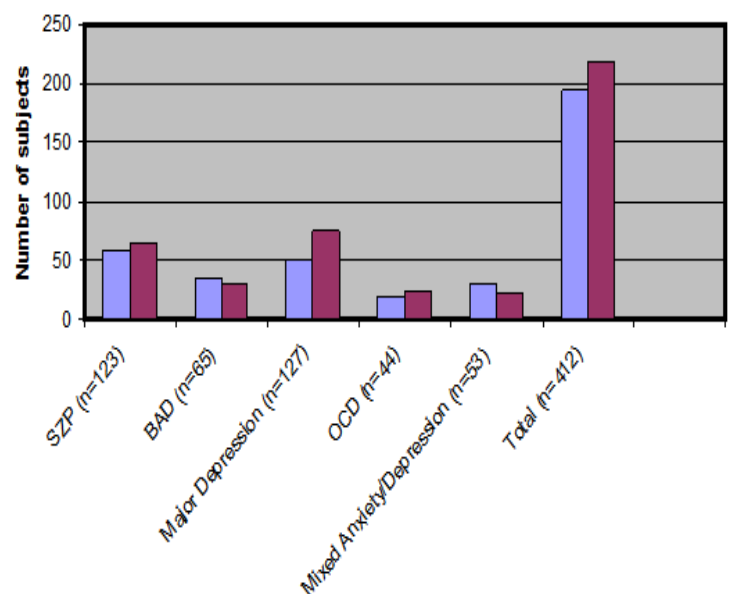

Diagnosis

Figure I Consanguineous and non-consanguineous subjects in relation to diagnosis.

The rate of consanguineous marriages in the sample population was $47.1 \%$. Table 2 shows the degree and the direction of relationship for consanguineous subjects using Chi square analysis. The commonest type of consanguineous marriages was first cousin marriage (71.1\%). The second type of consanguineous marriages was combination of second and third cousins (22.7\%) and lastly being from the same tribe $(6.2 \%)$. The direction of relationship for consanguineous subjects was mainly paternal $(62.9 \%)$, followed by maternal $(18.5 \%)$ and joined relationship (both parents) $(6.7 \%)$.

Table 2 Degree and direction of relationship for consanguineous subjects

\begin{tabular}{lccc}
\hline \multicolumn{1}{l}{ Number of subjects $(\mathbf{n = 1 9 4 )}$} & Frequency & $\%$ & P Value \\
\hline Degree of relationship & 138 & 71.1 & \\
First Cousin & & & \\
Second and Third Cousins & 44 & 22.7 & $0.000 * *$ \\
Same Tribe & 12 & 6.2 & \\
Direction of relationship & & & \\
Paternal & 122 & 62.9 & \\
Maternal & 36 & 18.5 & $0.000 * *$ \\
Joint (paternal and maternal) & 13 & 6.7 & \\
Missing data & 23 & 11.9 & \\
\hline
\end{tabular}

* Sig. at 0.05 level

** Sig. at 0.01

\section{Discussion}

The rate of consanguineous marriages in the study subjects was $47.1 \%$ which is within the same range of the result of Bener and $\mathrm{Al}$ Ali in Qatar. ${ }^{26}$ This result is not surprising as it falls within the range of results in the Middle East region as many previous results had found. ${ }^{2,12,18}$ After all, Qatar is inseparable from other countries in the region as it has similar traditions, cultural roots and shares similar values and religion particularly when it comes to marriage.

Similarly, the study did find similar rates of relationship marriages compared to previous studies. The most common marriage was between first cousins and it comprises almost 3 times of all other types of marriages. This was followed by marriages between second and third cousins combined and the last was marriages within the same tribe. Similar results were observed by Bener and Al Ali. ${ }^{9}$ This finding is also not uncommon as it is understandably based on the shared traditions, religion and values of participants as indicated above.

The direction of relationship for consanguineous subjects was mainly paternal and comprises to nearly two thirds of the consanguineous subjects (62.9\%) compared to maternal $18.5 \%$. Thus, paternal consanguinity union might be a strong predictor of consanguinity in the study population. Similar result was obtained by Bener and associates who found a third of marriages in the paternal generation being reported as consanguineous. ${ }^{17}$

The study did not find any significant differences between consanguineous and non-consanguineous subjects in relation to the diagnosis of the five major psychiatric disorders. The result is suggesting a multi-factorial model of causality rather than focusing solely in the genetic predisposition.

The study revealed that only $23.6 \%$ of participants have family history of mental illness, with consanguineous subjects reporting $12.9 \%$ and non-consanguineous $10.7 \%$ (Table 1).

On the other hand, family history was found to be associated with schizophrenia (31.7\%), bipolar disorder (27.7\%), major depression (16.6), and mixed anxiety and depression disorder (30.2\%), while obsessive compulsive disorder has the lowest percentage (6.8\%). This result is in agreement with the literature apart from the mixed anxiety and depression disorder group which was found to be slightly higher for which we do not have an explanation.

The duration of mental illness was also significantly associated with consanguinity and psychiatric disorders. As more than a third of participants $(32.5 \%)$ reported a duration of illness greater than 15 years indicating the severity of their psychiatric disorders which might also be exacerbated by other life stressors. $13.8 \%$ consanguineous subjects fall into this category while $18.7 \%$ were non-consanguineous subjects (Table 1).

Similarly, the duration of mental illness was also associated with the five major psychiatric disorders we are studying. Those diagnosed with major depression (41.7\%), mixed anxiety and depression $(39.6 \%)$, schizophrenia $(32.5 \%)$ had the longest illness duration. This might be due to a number of factors such as lack of adherence to prescribed medication or erratic attendance to appointments which can be attributed to patients, family, and/or system factors.

The majority of participants are unemployed, being the main income providers and not receiving social benefit. This might be due to the fact that most of those who are falling in this category are females who are naturally provided for by their families which is a deeply ingrained tradition in the Arabic and Islamic society.Moreover, Qatar is welfare state providing its unemployed or medically unfit citizens with social benefit which some individuals, who are receiving it do not want it to be disclosed because of fear of social stigma. 


\section{Limitations}

To the knowledge of the investigators, this study is the first of its kind to examine consanguineous marriages in relation to five major psychiatric disorders in the region, however, it is not without it is shortcomings. As the study sample is skewed and thus has the characteristic and disadvantages of such a sample. In spite of collecting the sample from the most comprehensive psychiatric service in the country, the investigators are aware that the current sample is not representative of the true size of the five psychiatric disorders in the country. This is due to the fact that some patients seek help in a variety of setting including, but not limited to, private practices, going abroad, attending faith and traditional healers or just remain undetected or have no accessibility to any kind of care. Deoxyribonucleic acid (DNA) which contains the unique genetic code, being the most accurate and confirmative method in providing and determining inbreeding, is not used in the study. The authors' felt It would be insulting and stigmatizing in a very conservative Islamic society which will be understood, if investigated, as if questioning the legitimacy of the marriage and pregnancy and thus would be inappropriate to ask such questions.

Further matched control group studies were needed preferably at the level of the Gulf Cooperation Council (GCC) as they shared a great deal of socio-demographic characteristics and cultural heritage and the Qatar National Mental Health Strategy is supporting such studies.

\section{Funding}

My research project was partially or fully sponsored by (Qatar National Research Fund NPRP) with grant number (4-086-5-007). In case of no financial assistance for the research work, provide the information regarding the sponsor.

\section{Acknowledgments}

This research report was made possible by the NPRP grant \# [4086-5-007] from the Qatar National Research Fund (a member of the Qatar Foundation). The statements made herein are solely the responsibility of the authors.

\section{Conflicts of interest}

The authors declare that there is no conflict of interest to declare.

\section{References}

1. Jaber L, Halpem GJ, Shohat M. The impact of consanguinity worldwide, Genet. 1998;1:12-17.

2. Rudan I, Smolej-Narancic N, Campbell H, et al. Inbreeding and genetic complexity of human hypertension, Genet. 2003;163(3):1011-1021.

3. Bittles AH. A community genetics perspective on consanguineous marriage, Community Genet. 2008;11:324-330.

4. Rudan I, Campbell H, Carothers AD, et al. Contribution of consanguinity to polygenic and multifactorial diseases. Nat Genet. 2006;38(11):122412245 .

5. Teebi A, Farag T. Genetic disorders among Arab populations, New York: Oxford University Press; 1997.

6. Al-Gazali LI, Bener A, Abdulrazzaq YM, et al. Consanguineous marriages in the United Arab Emirates. J Biosoc Sci. 1997;29(4):491-497.
7. Bener A, Abdulrazzaq YM, Al-Gazali LI, et al. Consanguinity and associated socio-demographic factors in the United Arab Emirates. Hum Hered. 1996;46(5):256-264.

8. Bener A, Al-Hamaq AO, Dafeeah EE. A two-fold risk of metabolic syndrome in a sample of patients with schizophrenia: do consanguinity and family history increase risk? Diab Metab Syndr. 2014;8(1):24-29.

9. Bener A, Alali KA. Consanguineous marriage in a newly developed country: the Qatari population. J Biosoc Sci. 2006;38(2):239-246.

10. Khoury SA, Massad D. Consanguineous marriage in Jordan, Am J Med Genet. 1992;15:43(5):769-775.

11. Gunaid AA, Hummad NA, Tamim KA. Consanguineous marriage in the capital city Sana'a, Yemen. J Biosoc Sci. 2004;36(1):111-121.

12. Tamim H, Khogali M, Beydoun H, et al. National Collaborative Perinatal Neonatal Network: Consanguinity and apnea of prematurity. Am J Epidemiol. 2003;15:158:942-946.

13. Abu Zeid Ahmed. The social structure: An introduction to study the society: Part two: System, the Egyptian organization for book, Alexandria, Egypt; 1979.

14. Al-Ghanim K. The Hierarchy of Authority Based on Kinship, Age, and Gender in the Extended Family in the Arab Gulf States. International Journal of the Jurisprudence of the Family.2013;3:481-497.

15. Al-Thaqb, Fahad. Family ties - kinship in contemporary society Kuwait. Journal of Human Sciences. 1982;(10):3-70.

16. State of Qatar. Planning and Statistics Authority. Marriage and Divorce Statistics. 2018

17. Bener A, Hussain R, Teebi AS. Consanguineous marriages and their effects on common adult diseases: studies from an endogamous population, Med Princ Pract. 2007;16:262-267.

18. Bittles AH, Mason WM, Greene J, et al. Reproductive behaviour and health in consanguineous marriages. Science. 1991;252(5007):789-794.

19. Abdulrazzaq YM, Bener A, Al-Gazali LI, et al. Study of possible deleterious effects of consanguinity. Clin Genet. 1997;51:167-173.

20. Mansour H, Klei L, Wood J, et al. Consanguinity associated with increased risk for bipolar I disorder in Egypt. Am J Med Genet B Neuropsychiatr Genet. 2009;5;150B(6):879-885.

21. Mansour H, Fathi W, Klei L, et al. Consanguinity and increased risk for schizophrenia in Egypt, Schizophr Res. 2010;120(1-3):108-112.

22. Chaleby K, Tuma TA. Cousin Marriages and schizophrenia in Saudi Arabia. Br J Psychiatry. 1987;150:547-549.

23. Ahmed AH. Consanguinity and schizophrenia in Sudan. Br J Psychiatry. 1979;134:635-636.

24. Bener A, Dafeeah EE, Samson N. Does consanguinity Increase the risk of schizophrenia? Study on primary health care center visits. Ment Health Fam Med. 2012;9:241-248.

25. Dobrusin M, Weitzman D, Levine J, et al. The rate of consanguineous marriages among parents of schizophrenic patients in the Arab Bedouin population in southern Israel, World J Biol Psychiatry. 2009;10:334-336.

26. Bener A, Hussain R. Consanguineous unions and child health in the State of Qatar. Paediatr Perinat Epidemiol. 2006;20(5):372-378.

27. Alshawi, AH, Andrew Gardner. Tribalism, Identity and Citizenship in Contemporary Qatar, Anthropology of the Middle East. 2013;8(2):46-59.

28. Stat of Qatar. Authority of Planning and Statistics, Annual Bulletin of Vital Statistics: Marriages and Divorces. 2018:12-15. 